Check for updates

Cite this: RSC Adv., 2017, 7, 50195

Received 13th September 2017 Accepted 23rd October 2017

DOI: 10.1039/c7ra10182a

rsc.li/rsc-advances

\title{
High-pressure synthesis, crystal structure and photoluminescence properties of a new terbium silicate: $\mathrm{Na}_{2} \mathrm{~Tb}_{1.08} \mathrm{Ca}_{2.92} \mathrm{Si}_{6} \mathrm{O}_{18} \mathrm{H}_{0.8} \dagger$
}

\author{
Xinjian Bao, ${ }^{\text {abc }}$ Xiaoyang Liu (D) ${ }^{c}$ and Xi Liu (D) *ab
}

\begin{abstract}
The crystal properties of a terbium silicate $\mathrm{Na}_{2} \mathrm{~Tb}_{1.08} \mathrm{Ca}_{2.92} \mathrm{Si}_{6} \mathrm{O}_{18} \mathrm{H}_{0.8}$ synthesized at $1 \mathrm{GPa}$ and $800{ }^{\circ} \mathrm{C}$ using a piston-cylinder apparatus is reported. Our single-crystal $X$-ray analysis shows that this new compound is triclinic with the space group $\bar{P} 1(Z=1)$, and its unit-cell parameters are $a=7.056(3) \AA, b=7.075(3) \AA, c=$ $8.029(3) \AA, \alpha=102.381(5)^{\circ}, \beta=95.387(6)^{\circ}, \gamma=90.552(6)^{\circ}$, and $V=389.6(2) \AA^{3}$. This structure consists of octahedral double chains of the compositions $\left[\mathrm{Ca}_{0.875} \mathrm{~Tb}_{0.125} \mathrm{O}_{6}\right]$ and $\left[\mathrm{Ca}_{0.585} \mathrm{~Tb}_{0.415} \mathrm{O}_{6}\right]$. The double chains are linked by tetrasilicate chains via vertex oxygen atoms to form a 3D framework with 6-membered (2 octahedra and 4 tetrahedra) ring channels along the $b$-axis where the $\mathrm{Na}^{+}$cations locate. The luminescence properties of the $\mathrm{Na}_{2} \mathrm{~Tb}_{1.08} \mathrm{Ca}_{2.92} \mathrm{Si}_{6} \mathrm{O}_{18} \mathrm{H}_{0.8}$ phase are also investigated. This phase, with most of its $\mathrm{Tb}$ in $3+$, emits mainly from one transition, ${ }^{5} \mathrm{D}_{4} \rightarrow{ }^{7} \mathrm{~F}_{5}$ (542 and $552 \mathrm{~nm}$ ). The room temperature fluorescence decay curves are fit well by an exponential function, yielding a lifetime value of about $2.498(7) \mathrm{ms}$.
\end{abstract}

\section{Introduction}

Microporous lanthanide-containing silicates constitute a novel family of zeotype materials made of interlinked octahedra and tetrahedra. Many studies have focused on the synthesis of this group of compounds for their versatility in terms of chemical compositions, framework topologies and ion-exchange properties, as well as their interesting physical and chemical properties. $^{1-5}$ Due to their high thermal stability and tunable optical properties, the lanthanide-containing silicates attract much interest as candidates of optical materials..$^{6-8}$ In 1997, Rocha et al. reported a microporous sodium yttrium silicate $\mathrm{Na}_{4} \mathrm{~K}_{2} \mathrm{Y}_{2} \mathrm{Si}_{16} \mathrm{O}_{38^{-}}$ $\cdot 10 \mathrm{H}_{2} \mathrm{O} .{ }^{9}$ Since then a series of microporous lanthanide silicates have been successfully prepared. Recently, many studies have focused on the possibility to obtain phosphors with emission across the entire visible range by selection of lanthanide ions. ${ }^{\mathbf{1 0 - 1 3}}$

High-pressure (HP) experimental techniques have been usually employed in synthesizing the lanthanide-containing silicates in recent decades. As a few examples, Huang et al. documented the HP synthesis of a new europium silicate $\mathrm{Cs}_{3}$ $\mathrm{EuSi}_{6} \mathrm{O}_{15}$, which consists of loop-branched vierer double chains

${ }^{a}$ Key Laboratory of Orogenic Belts and Crustal Evolution, MOE, Peking University, Beijing 100871, China. E-mail: xi.liu@pku.edu.cn; Fax: +86-10-6275-2996; Tel: +8610-6275-3585

${ }^{b}$ School of Earth and Space Sciences, Peking University, Beijing 100871, China

${ }^{c}$ State Key Laboratory of Inorganic Synthesis and Preparative Chemistry, College of Chemistry, Jilin University, Changchun 130012, China

$\dagger$ Electronic supplementary information (ESI) available. CCDC 1574110. For ESI and crystallographic data in CIF or other electronic format see DOI: 10.1039/c7ra10182a of silicate with four-, six-, and eight-membered rings; ${ }^{3}$ Zhao et al. reported the HP synthesis of three new lanthanide silicates based on anionic silicate chain, layer, and framework. ${ }^{\mathbf{1 4}}$ Liu's group synthesized a number of lanthanide-containing silicates under HP conditions and reported their structural features. ${ }^{15-18}$

In this work a new terbium silicate, $\mathrm{Na}_{2} \mathrm{~Tb}_{1.08} \mathrm{Ca}_{2.92} \mathrm{Si}_{6} \mathrm{O}_{18}$ $\mathrm{H}_{0.8}$, was synthesized at HP condition using a piston-cylinder apparatus. The crystallographic details of this phase were obtained by performing single-crystal X-ray diffraction analysis, and the luminescence properties were systematically investigated using a range of analytical techniques as well.

\section{Experiment}

\subsection{Synthesis}

The starting material was made as following: pure chemicals $\mathrm{NaOH} \cdot \mathrm{H}_{2} \mathrm{O}$ (Alfa Aesar, powder, 99.9\%), $\mathrm{TbCl}_{3} \cdot 6 \mathrm{H}_{2} \mathrm{O}$ (Alfa Aesar, powder, 99.9\%), $\mathrm{CaCO}_{3}$ (Alfa Aesar, powder, 99.9\%) and $\mathrm{SiO}_{2}$ (Alfa Aesar, powder, 99.9\%) were weighed without any pretreatment, ground and homogenized in an agate mortar. This mixture was subsequently stored in a drying oven at $110{ }^{\circ} \mathrm{C}$ for later synthesizing experiment. The molar ratio of these chemicals in the starting material was ideally $\mathrm{NaOH} \cdot \mathrm{H}_{2} \mathrm{O}: \mathrm{TbCl}_{3} \cdot 6 \mathrm{H}_{2} \mathrm{O}: \mathrm{CaCO}_{3}: \mathrm{SiO}_{2}=2: 1: 3: 6$, leading to $\sim 11.9 \mathrm{wt} \% \mathrm{CO}_{2}$ and $11.32 \mathrm{wt} \% \mathrm{H}_{2} \mathrm{O}$ in the bulk composition. The starting material was loaded into a Pt capsule, which was sealed at both ends using an arc-welding technique. Our synthesizing experiment was carried out with a piston-cylinder apparatus (Depths of The Earth Company Quickpress ${ }^{\mathbf{1 9 , 2 0}}$ ). The experimental assembly and high-P experimental technique were 
generally identical to those reported in. ${ }^{21}$ Our sample was synthesized at $1 \mathrm{GPa}$ and $800{ }^{\circ} \mathrm{C}$ with a heating time of 24 hours. After the reaction, the sample was quickly cooled down to room temperature by switching off the electrical power supply. Some parts of the resulting sample were first crushed, then treated with diluted $\mathrm{HCl}$ to remove any possible residues of carbonate and hydrate, and finally washed with deionized water for further test.

\subsection{Characterizations}

Powder X-ray diffraction (XRD) data were collected using a Rigaku D/Max 2550 V/PC X-ray diffractometer with graphitemonochromated $\mathrm{Cu} \mathrm{K} \alpha$ radiation $(\lambda=0.15418 \mathrm{~nm})$ at $50 \mathrm{kV}$ and $200 \mathrm{~mA}$ at room temperature. Energy-dispersive spectroscopy (EDS) analysis was carried out using an EDS system attached to a JEOL JXA-8100 electron microprobe. The instrument was calibrated using a series of standards from Structure Probe, Inc. XPS valence band spectra were obtained with an ESCA LAB 250 photoelectron spectrometer. IR spectrum was recorded on a Nicolet Impact 410 FT-IR spectrometer using the $\mathrm{KBr}$ pellet technique. Thermogravimetric analysis (TG) was carried out on a Perkin-Elmer TGA unit in air with a heating rate of $10{ }^{\circ} \mathrm{C} \mathrm{min}{ }^{-1}$. Photoluminescence (PL) spectra were obtained on a F7000 (Hitachi) spectrophotometer with Xe 900 (150 W xenon arc lamp) as the light source. PL decay curves were measured on an FLS980 spectrophotometer (Edinburgh Instruments) with an $\mathrm{mF} 90 \mathrm{H}$ flash lamp as the light source. To eliminate the second-order emission from the source radiation, a cut-off filter was used during the measurement. Slit widths were 0.20 (excitation) and 0.20 (emission) $\mathrm{nm}$. All spectra were recorded at room temperature.

\subsection{Single-crystal X-ray diffraction}

Suitable single crystal was selected for single-crystal X-ray diffraction analysis. Intensity data was collected on a Bruker Smart ApexII Quazar micro-focused diffractometer using Mo K $\alpha$ radiation $(\lambda=0.71073 \mathrm{~nm})$. The raw data was processed and corrected for the absorption effects using SAINT ${ }^{+}$and SADAB. An initial structure solution was obtained via direct methods and refined by a full-matrix least-squares method using the SHELXT software included in the SHELXTL package. All heavy atoms ( $\mathrm{Na}, \mathrm{Tb}, \mathrm{Ca}$, and $\mathrm{Si}$ ) were first located unambiguously in the Fourier maps, and then the $\mathrm{O}$ atoms were found in the subsequent difference maps. All atoms were refined with anisotropic displacement parameters. The final cycles of the least-squares refinement including atomic coordinates and anisotropic thermal parameters for the atoms $[I>2 \operatorname{sigma}(I)]$ converged at $R_{1}=0.0502, \mathrm{w} R_{2}=0.1186$, and $S=1.015$ for this new terbium silicate compound.

\section{Results and discussion}

\subsection{Phases in synthetic material}

The SEM backscatter image shown in Fig. $\mathrm{S} 1 \dagger$ indicates that there is just one crystalline phase in our synthetic product, in good agreement with our powder XRD data. The powder XRD

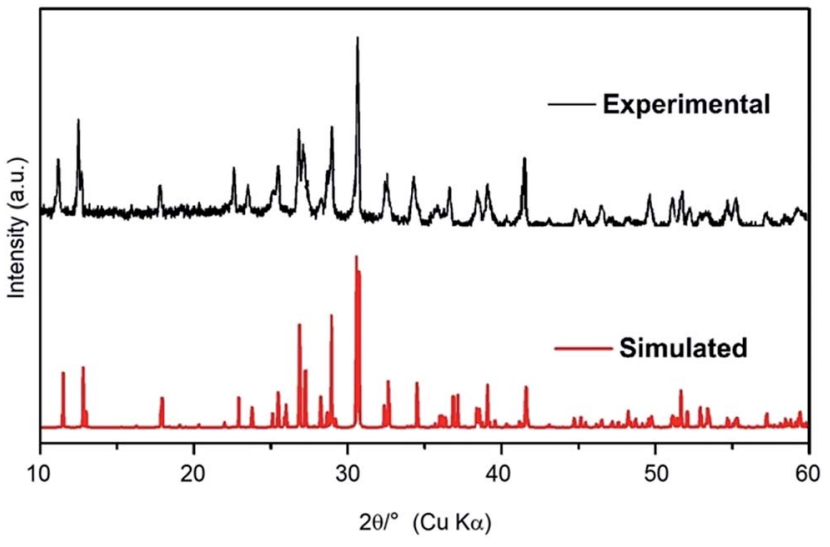

Fig. 1 Experimental and simulated powder $\mathrm{X}$-ray diffraction patterns of the $\mathrm{Na}_{2} \mathrm{~Tb}_{1.08} \mathrm{Ca}_{2.92} \mathrm{Si}_{6} \mathrm{O}_{18} \mathrm{H}_{0.8}$ compound. The simulated pattern is based on the structure refined by our single-crystal $\mathrm{X}$-ray diffraction analysis.

pattern of the experimental product is shown in Fig. 1; since it is completely consistent with the simulated XRD pattern based on our single-crystal structure data (to be reported in the next Section), one crystalline phase in the experimental product is the only possible explanation. In addition, Fig. $\mathrm{S} 1 \dagger$ reveals significant amount of holes and cracks in the sample, suggesting the role of a $\mathrm{C}-\mathrm{H}-\mathrm{O}$ fluid phase in our experiment; note that there was $\sim 23.22$ wt\% $\mathrm{CO}_{2}$ and $\mathrm{H}_{2} \mathrm{O}$ in the starting material. Ten EDS analyses performed on arbitrarily selected areas of the experimental product suggest a cation ration of $\mathrm{Na}: \mathrm{Tb}: \mathrm{Ca}: \mathrm{Si}=2: 1.08: 2.92: 6$, slightly different from the original and ideal cation ration of $\mathrm{Na}: \mathrm{Tb}: \mathrm{Ca}: \mathrm{Si}=2: 1: 3: 6$ in the bulk composition. This compositional difference partially reflects a possible drawback of using untreated chemicals to

Table 1 Crystal data and structure refinement for the $\mathrm{Na}_{2} \mathrm{~Tb}_{1.08^{-}}$ $\mathrm{Ca}_{2.92} \mathrm{Si}_{6} \mathrm{O}_{18} \mathrm{H}_{0.8}$ compound

Empirical formula

Formula weight

Temperature

Wavelength

Crystal system, space group

Unit cell dimensions

Volume

$Z$

Crystal size

Theta range for data collection Limiting indices

Reflections collected/unique

Completeness to theta $=25.10$

Refinement method

Data/restraints/parameters

Goodness-of-fit on $F^{2}$

Final $R$ indices $[I>2 \operatorname{sigma}(I)]$

$R$ Indices (all data)

Largest diff. Peak and hole

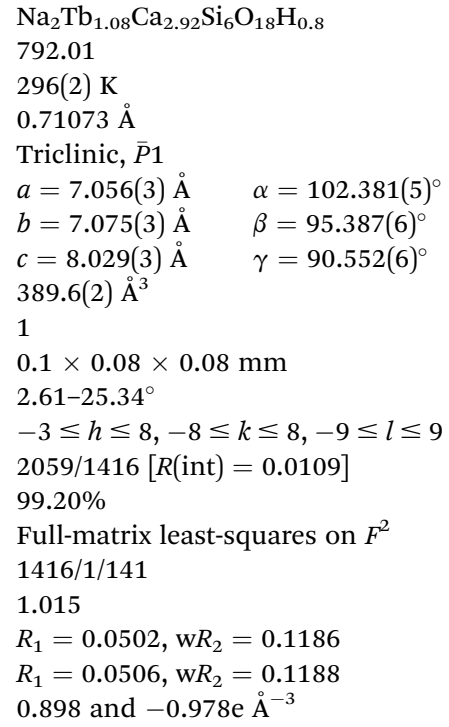


prepare the starting material, and partially implies that the $\mathrm{C}-\mathrm{H}-\mathrm{O}$ fluid was not pure, but dissolved some $\mathrm{Na}, \mathrm{Ca}$ and $\mathrm{Si}$.

Combined with the single-crystal structure data, XPS data, FT-IR data and TG data reported below, the composition of this crystalline phase has been approximated by the chemical formula of $\mathrm{Na}_{2} \mathrm{~Tb}_{1.08} \mathrm{Ca}_{2.92} \mathrm{Si}_{6} \mathrm{O}_{18} \mathrm{H}_{0.8}$.

\subsection{Single-crystal structure}

The single-crystal analysis of the $\mathrm{Na}_{2} \mathrm{~Tb}_{1.08} \mathrm{Ca}_{2.92} \mathrm{Si}_{6} \mathrm{O}_{18} \mathrm{H}_{0.8}$ silicate reveals that it crystallizes in the $\bar{P} 1$ space group $(Z=1)$, with $a=7.056(3) \AA, b=7.075(3) \AA, c=8.029(3) \AA, \alpha=102.381(5)^{\circ}$, $\beta=95.387(6)^{\circ}, \gamma=90.552(6)^{\circ}$, and $V=389.6(2) \AA^{3}$ (Table 1). Each asymmetric unit of this new terbium silicate compound contains one distinct $\mathrm{Na}$ site, two distinct $\mathrm{Ca}(\mathrm{Tb})$ sites (denoted as M1 and M2), three distinct Si site and nine distinct $\mathrm{O}$ sites (Fig. S2 $\dagger$ ), with their coordinates and equivalent isotropic displacement parameters being listed in Table S1. $\dagger$

This novel $\mathrm{Na}_{2} \mathrm{~Tb}_{1.08} \mathrm{Ca}_{2.92} \mathrm{Si}_{6} \mathrm{O}_{18} \mathrm{H}_{0.8}$ compound has a $3 \mathrm{D}$ framework structure (Fig. 2). Two distinct $\left[\mathrm{MO}_{6}\right]$ octahedra form edge-sharing double chains running along the $b$-axis. The $\left[\mathrm{SiO}_{4}\right]$ tetrahedron in the crystal structure is linked to two adjacent $\left[\mathrm{SiO}_{4}\right]$ tetrahedra, these three symmetrically independent $\left[\mathrm{SiO}_{4}\right]$ tetrahedra form a C-shaped cluster, and neighboring C-shaped clusters are linked via sharing $\mathrm{O}$ atoms to form a zigzag chain along the $b$ axis. The tetrahedral chain is linked to the double chains of the $\left[\mathrm{MO}_{6}\right]$ through corner-sharing. The stacking pattern along with the linkages between the layers of tetrahedra and octahedra gives rise to an I-beam topology where bands of the octahedra are linked to overlying and underlying silicate chains through the apical $\mathrm{O}$ atoms in the $\left[\mathrm{SiO}_{4}\right]$ tetrahedra. The resulting framework contains 4-membered and 6-membered ring channels along the $b$-axis, where the $\mathrm{H}$ and $\mathrm{Na}$ cations locate, respectively.

The $\mathrm{Ca}$ and $\mathrm{Tb}$ atoms are disordered over the M1 and M2 sites with different occupancies. In the M1 and M2 sites, the Ca occupancies are 0.875 and 0.585 , respectively. The corresponding structural formula is thus $\mathrm{Na}_{2}\left(\mathrm{~Tb}_{0.25} \mathrm{Ca}_{1.75}\right) \quad\left(\mathrm{Tb}_{0.83} \mathrm{Ca}_{1.17}\right)$ $\mathrm{Si}_{6} \mathrm{O}_{18} \mathrm{H}_{0.8}$. As shown in Fig. 2 and Table $\mathrm{S} 2, \uparrow$ all the $\mathrm{M}$ sites are coordinated to six bridging $\mathrm{O}$ atoms to form $\left[\mathrm{MO}_{6}\right]$ octahedra. For the $\mathrm{M}_{1} \mathrm{O}_{6}$, the lengths of the six M1-O bands lie between 2.295(8) to $2.491(8) \AA$ while the O-M1-O angles from $79.4(3)$ to $167.9(3)^{\circ}$.

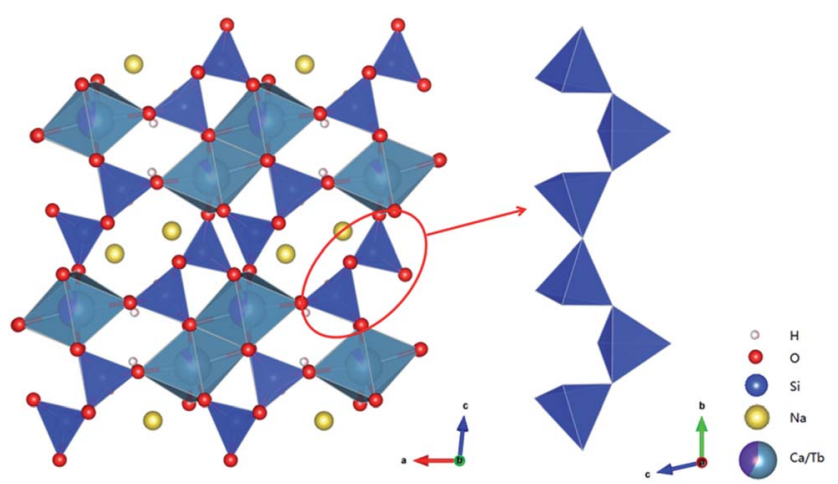

Fig. 2 Polyhedral view of the $\mathrm{Na}_{2} \mathrm{~Tb}_{1.08} \mathrm{Ca}_{2.92} \mathrm{Si}_{6} \mathrm{O}_{18} \mathrm{H}_{0.8}$ compound along the $b$-axis and $\left[\mathrm{SiO}_{4}\right]$ tetrahedra single chain.
For the $\mathrm{M}_{2} \mathrm{O}_{6}$, the $\mathrm{M} 2-\mathrm{O}$ band lengths are in the range from 2.281(7) to 2.474(8) $\AA$ while the O-M2-O angles from 80.8(3) to $176.6(3)^{\circ}$. The $\mathrm{Tb}$ atoms on these two sites have mixed valences, with the $\mathrm{Tb}^{3+}$ dominant: the XPS spectrum (Fig. S3†) shows two main peaks at $\sim 148.11$ and $150.27 \mathrm{eV}$, which are attributed to the $\mathrm{Tb}^{3+}$ and $\mathrm{Tb}^{4+}$, respectively; the ratio of $\mathrm{Tb}^{4+}: \mathrm{Tb}$ has been calculated as $\sim 0.194$ by performing peak-area analysis. ${ }^{22}$ On the basis of charge balance, furthermore, the XPS data imply $\sim 0.7 \mathrm{H}$ in the unit cell of the crystal structure.

The $\mathrm{Si}$ atoms are all in 4-fold coordination, and form $\left[\mathrm{SiO}_{4}\right]$ tetrahedra. The Si-O lengths vary from 1.601(8) to 1.645(7) A for the $\mathrm{Si}_{1}-\mathrm{O}$ bonds, from 1.577(8) to 1.647(7) $\AA$ for the $\mathrm{Si}_{2}-\mathrm{O}$ bonds, and from $1.593(7)$ to $1.666(7) \AA$ for the $\mathrm{Si}_{3}-\mathrm{O}$ bonds. The O-Si-O angles are shown in Table $\mathrm{S} 2 . \dagger$

The hydrogen site $\left(\mathrm{H}_{1}-\mathrm{O}_{1}\right)$ has been confirmed by the electron density difference following the ref. 23,24. The hydrogen bond length was fixed as $0.84 \AA$ during the refinement. In addition, the existence of the $\mathrm{O}-\mathrm{H}$ bond has been confirmed by our IR analysis (Fig. S4 $\dagger$ ): the peaks at $\sim 3500 \mathrm{~cm}^{-1}$ in the IR spectrum can be assigned to the $\mathrm{O}-\mathrm{H}$ stretching bands. Further, the existence of the $\mathrm{OH}$ group in our new terbium silicate compound has been confirmed by the thermogravimetric analysis. As shown in Fig. S5, $\uparrow$ the TG curve of the compound revealed a weight loss of $\sim 1 \mathrm{wt} \%$ in the temperature range of $\sim 300-650{ }^{\circ} \mathrm{C}$. At temperatures higher than $650{ }^{\circ} \mathrm{C}$, no significant weight loss occurred, indicating that the sample was almost anhydrous at relatively high temperatures. The TG data thus suggests approximately $0.88 \mathrm{H}$ in the unit cell of this compound, a result in excellent agreement with that required by the XPS and EDS data if the experimental uncertainty in the TG analysis is taken into account.

With the knowledge of the cation-anion distances from Shannon, ${ }^{25}$ the Na cation is coordinated to six $\mathrm{O}$ atoms with the $\mathrm{Na}-\mathrm{O}$ bond lengths ranging from 2.295(8) to 2.502(8) A. There are two more $\mathrm{O}$ atoms, with the distances of 2.967(9) and 2.991(9) A, surrounding the Na atom as well.

Table S3† presents the calculated bond valence sums (BVSs). ${ }^{26,27}$ The BVSs for the $\mathrm{Si}^{4+}$ cations are in good accordance with their theoretical values of $4.0 \mathrm{v}$.u. The total valences of the $\mathrm{M}$ cations are 9.2 v.u. depending on the formula, and the BVSs for the $\mathrm{M}$ cations are 9.376 v.u. which deviates slightly from the theoretical value by $1.02 \%$. All $\mathrm{O}$ atoms show BVSs more or less close to their ideal values of $2.0 \mathrm{v}$.u. The relatively low values for $\mathrm{O}_{1}$ (1.512 v.u.) and $\mathrm{O}_{7}$ (1.618 v.u.) are explained by their connection to the $\mathrm{H}^{+}$cation. Taking into account the Tb occupation and BVSs of the $\mathrm{M}$ cations, the compositions of the cations on the M1 and M2 sites are tentatively determined as $\mathrm{Ca}_{0.875}^{2+} \mathrm{Tb}_{0.125}^{4+}$ and $\mathrm{Ca}_{0.585}^{2+} \mathrm{Tb}_{0.415}^{3+}$, respectively. With the cation radius data from Shannon, ${ }^{25}$ the average cation radii of the M1 and M2 sites are calculated as 0.970 and $0.968 \AA$, respectively. It means that the coordination environments of the M1 and M2 sites are generally similar.

\subsection{Photoluminescent studies}

Fig. 3 shows the room temperature excitation spectra of the $\mathrm{Na}_{2} \mathrm{~Tb}_{1.08} \mathrm{Ca}_{2.92} \mathrm{Si}_{6} \mathrm{O}_{18} \mathrm{H}_{0.8}$ phase, monitored within the 


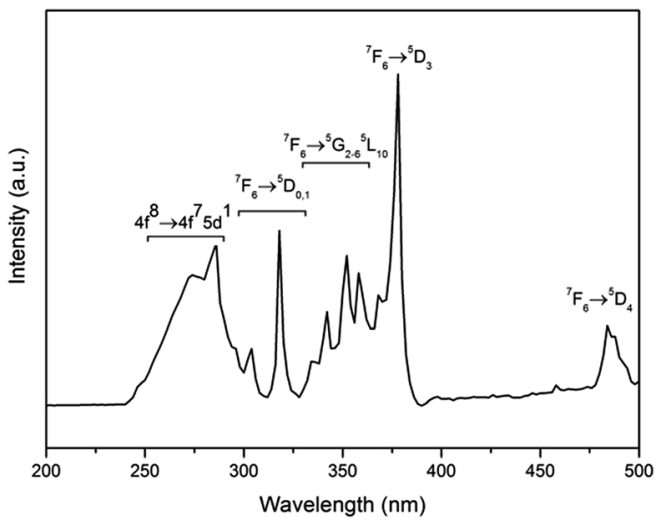

Fig. 3 Excitation spectrum of $\mathrm{Na}_{2} \mathrm{~Tb}_{1.08} \mathrm{Ca}_{2.92} \mathrm{Si}_{6} \mathrm{O}_{18} \mathrm{H}_{0.8}\left(\lambda_{\mathrm{em}}=542\right.$ $\mathrm{nm})$.

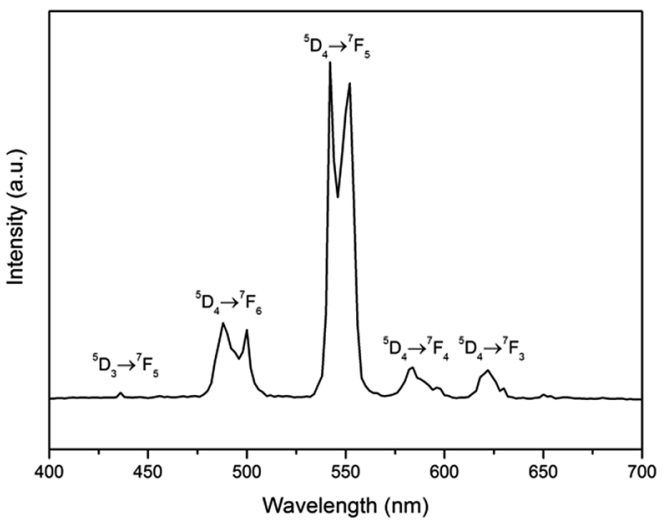

Fig. 4 RT emission spectra of $\mathrm{Na}_{2} \mathrm{~Tb}_{1.08} \mathrm{Ca}_{2.92} \mathrm{Si}_{6} \mathrm{O}_{18} \mathrm{H}_{0.8}\left(\lambda_{\mathrm{em}}=378\right.$ $\mathrm{nm})$.

$\mathrm{Tb}^{3+5} \mathrm{D}_{4} \rightarrow{ }^{7} \mathrm{~F}_{5}$ transition (542 nm). In the excitation spectrum, the sharp lines between 320 and $500 \mathrm{~nm}$ are assigned as the intraconfigurational $4 \mathrm{f}^{8}$ transitions of the $\mathrm{Tb}^{3+}$ between the ${ }^{7} \mathrm{~F}_{6}$ ground state and the ${ }^{5} \mathrm{D}_{0,1},{ }^{5} \mathrm{G}_{2-6},{ }^{5} \mathrm{~L}_{10}$, and ${ }^{5} \mathrm{D}_{3,4}$ excited levels. On the other hand, the broad feature between $\sim 240$ and $320 \mathrm{~nm}$ may be contributed by both the spin-forbidden and spinallowed interconfigurational ${ }^{4} \mathrm{f}_{8} \rightarrow{ }^{4} \mathrm{f}_{7}{ }^{5} \mathrm{~d}_{1}$ (f-d) transitions of the $\mathrm{Tb}^{3+} ;{ }^{28,29}$ specifically, the bands at $\sim 275 \mathrm{~nm}$ can be assigned to the spin-allowed ${ }^{7} \mathrm{D}$ levels of the $4 \mathrm{f}^{8} \rightarrow 4 \mathrm{f}^{7} 5 \mathrm{~d}$ transition while the bands at $\sim 300 \mathrm{~nm}$ can be assigned to the spin-forbidden ${ }^{9} \mathrm{D}$ levels of the $4 \mathrm{f}^{8} \rightarrow 4 \mathrm{f}^{7} 5 \mathrm{~d}$ transition of the $\mathrm{Tb}^{3+}$ ions.

Fig. 4 shows the RT emission spectrum of the $\mathrm{Na}_{2} \mathrm{~Tb}_{1.08}$ $\mathrm{Ca}_{2.92} \mathrm{Si}_{6} \mathrm{O}_{18} \mathrm{H}_{0.8}$ phase. The emission spectrum excited at $378 \mathrm{~nm}\left(\mathrm{~Tb}^{3+5} \mathrm{D}_{3}\right)$ displays a series of sharp lines from 475 to $675 \mathrm{~nm}$, which are associated with the ${ }^{5} \mathrm{D}_{4} \rightarrow{ }^{7} \mathrm{~F}_{3-6}$ transitions of the $\mathrm{Tb}^{3+}$, with the strongest at about 542 and $552 \mathrm{~nm}\left({ }^{5} \mathrm{D}_{4} \rightarrow\right.$ ${ }^{7} \mathrm{~F}_{5}$ ). No apparent emission from the $\mathrm{Tb}^{4+}$ ion is expected in this range due to the charge transfer. ${ }^{30}$ Luminescence from any higher excited states (e.g., $\left.{ }^{5} \mathrm{D}_{3}\right)$ is very weak. The peak at $436 \mathrm{~nm}$ is assigned to the transition ${ }^{5} \mathrm{D}_{3} \rightarrow{ }^{7} \mathrm{~F}_{5}$. Other potential emissions with origins from the ${ }^{5} \mathrm{D}_{3}$ to ${ }^{7} \mathrm{~F}_{\mathrm{j}}$ transitions of the $\mathrm{Tb}^{3+}$ ions are not detected due to the cross-relaxation effect. ${ }^{31}$

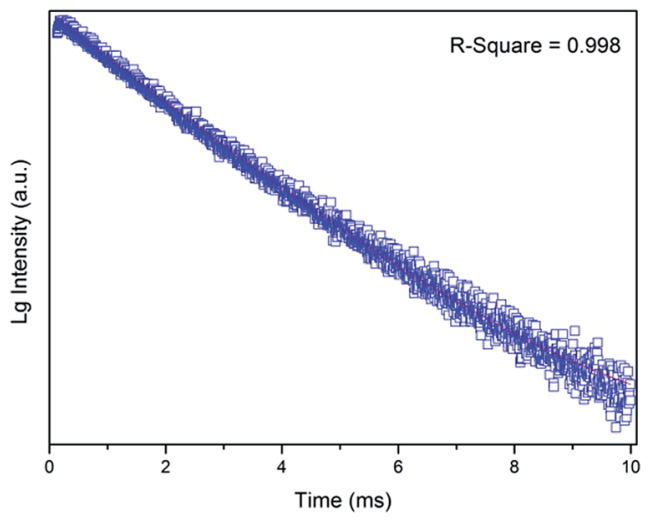

Fig. 5 RT fluorescence decay curve detected at $542 \mathrm{~nm}\left(\lambda_{\mathrm{em}}=276\right.$ $\mathrm{nm}$ ). The solid line represents the best fit to the data.

The RT fluorescence decay curve of the ${ }^{5} \mathrm{D}_{4} \rightarrow{ }^{7} \mathrm{~F}_{5}$ transitions (542 nm) for the $\mathrm{Na}_{2} \mathrm{~Tb}_{1.08} \mathrm{Ca}_{2.92} \mathrm{Si}_{6} \mathrm{O}_{18} \mathrm{H}_{0.8}$ phase (Fig. 5) is well fitted by the single exponential function, yielding the lifetime value of $\tau=2.498(7) \mathrm{ms}$, which is in good agreement with the reported value for the $\mathrm{Tb}^{3+}$ emission. ${ }^{32}$

\section{Implication}

Rare earth element-doped chain silicates, such as the $\mathrm{MSiO}_{3}(\mathrm{M}$ $=\mathrm{Mg}, \mathrm{Ca}, \mathrm{Sr}, \mathrm{Ba}$ ) solid solutions, form a very important group of photoluminescence materials, with different $\mathrm{M}$-site cations leading to different photoluminescence spectra. ${ }^{33-35}$ Furthermore, there are usually multiple $\mathrm{M}$ sites in these silicates. When these $\mathrm{M}$ sites are occupied by different rare earth elements, different luminescence properties are resulted in. In the case of the $\mathrm{Eu}^{2+}$-doped $\mathrm{NaScSi}_{2} \mathrm{O}_{6}-\mathrm{CaMgSi}_{2} \mathrm{O}_{6}$ solid solutions, ${ }^{36}$ as an example, the color-tunable photoluminescence feature was ascribed to the different local $\mathrm{M}$-site environments of the $\mathrm{Eu}^{2+}$. Accordingly, it's important to investigate the rare earth element distribution on the $\mathrm{M}$ sites. In this study, we have analyzed the $\mathrm{Tb}$ distribution of the chain silicate $\mathrm{Na}_{2} \mathrm{~Tb}_{1.08} \mathrm{Ca}_{2.92} \mathrm{Si}_{6} \mathrm{O}_{18} \mathrm{H}_{0.8}$ on its different $\mathrm{M}$ sites using single-crystal data. Combined with the BVSs, the valences of the Tb have been constrained as well. On the other hand, it remains to be explored whether the structure of this new phase, plus its optical properties, has strong dependence on the substitution between $\mathrm{Tb}$ and $\mathrm{Ca}$ on the $\mathrm{M}$ sites. We believe that the result reported here should stimulate further research on rare earth element-doped silicate photoluminescence materials.

\section{Conclusions}

In summary, a new microporous compound, with the composition of $\mathrm{Na}_{2} \mathrm{~Tb}_{1.08} \mathrm{Ca}_{2.92} \mathrm{Si}_{6} \mathrm{O}_{18} \mathrm{H}_{0.8}$ and a novel 3-D framework, has been synthesized under HP conditions. The structure of this phase can be viewed as made of some $\left[\mathrm{MO}_{6}\right]$ polyhedron double chains and zigzag $\left[\mathrm{SiO}_{4}\right]$ tetrahedron single chains. The $\left[\mathrm{MO}_{6}\right]$ polyhedron double chains, in parallel to the $b$-axis, are connected by neighboring $\mathrm{SiO}_{4}$ tetrahedron via vertex oxygen atoms to form a three-dimensional framework. This new phase 
contains large 6-membered ring channels along the $b$-axis direction, which are delimited by the $\left[\mathrm{SiO}_{4}\right]$ tetrahedra and $\left[\mathrm{MO}_{6}\right]$ polyhedra. Its photoluminescence studies are consistent with the crystallographic results, suggesting a strong green emission and a lifetime value of 2.498(7) ms. The successful synthesis of this new terbium silicate under HP conditions and the research on the rare earth element distribution on the $\mathbf{M}$ sites will stimulate further study on the lanthanide silicates with novel structures and useful optical properties.

\section{Conflicts of interest}

There are no conflicts to declare.

\section{Acknowledgements}

This study was financially supported by the Strategic Priority Research Program (B) of Chinese Academy of Sciences (Grant No. XDB18000000), by the DREAM project of MOST, China (Grant No. 2016YFC0600408), and by the Program of the Data Integration and Standardization in the Geological Science and Technology from MOST, China (Grant No. 2013FY1109000-3).

\section{Notes and references}

1 D. Ananias, M. Kostova, F. A. A. Paz, A. Ferreira, L. D. Carlos, J. Klinowski and J. Rocha, J. Am. Chem. Soc., 2004, 126, 10410.

2 G. Wang, J. Li, J. Yu, P. Chen, Q. Pan, H. Song and R. Xu, Chem. Mater., 2006, 18, 5637.

3 M. Y. Huang, Y. H. Chen, B. C. Chang and K. H. Lii, Chem. Mater., 2005, 17, 5743.

4 J. Rocha, L. D. Carlos, F. A. A. Paz and D. Ananias, Chem. Soc. Rev., 2011, 40, 926.

5 D. Ananias, F. A. A. Paz, L. D. Carlos and J. Rocha, Microporous Mesoporous Mater., 2013, 166, 50.

6 L. D. Sanjeewa, K. Fulle, C. D. McMillen, F. Wang, Y. f. Liu, J. He, J. N. Anker and J. W. Kolis, Solid State Sci., 2015, 48, 256.

7 D. Ananias, F. A. A. Paz, D. S. Yufit, L. D. Carlos and J. Rocha, J. Am. Chem. Soc., 2015, 137, 3051.

8 M. Wierzbicka-Wieczorek, M. Göckeritz, U. Kolitsch, C. Lenz and G. Giester, Eur. J. Inorg. Chem., 2015, 2015, 2426.

9 J. Rocha, P. Ferreira and Z. Lin, Chem. Commun., 1997, 21, 2103.

10 D. Ananias, A. Ferreira, J. Rocha, P. Ferreira, J. P. Rainho, C. Morais and L. D. Carlos, J. Am. Chem. Soc., 2001, 123, 5735-5742.
11 A. Ferreira, D. Ananias, L. D. Carlos, C. M. Morais and J. Rocha, J. Am. Chem. Soc., 2003, 125, 14573.

12 J. Rocha, P. Ferreira, Z. Lin, P. Brandão, A. Ferreira and J. D. P. d. Jesus, J. Phys. Chem. B, 1998, 102, 4739.

13 H. Chen, C. X. Li, Y. J. Hua, L. L. Yu, Q. Y. Jiang, D. G. Deng, S. L. Zhao, H. P. Ma and S. Q. Xu, Ceram. Int., 2014, 40, 1979.

14 X. G. Zhao, J. Y. Li, P. Chen, Y. Li, Q. X. Chu, X. Y. Liu, J. H. Yu and R. R. Xu, Inorg. Chem., 2010, 49, 9833.

15 C. Wang, X. Liu, M. E. Fleet, S. Fenga and R. Xua, J. Solid State Chem., 2006, 179, 2245.

16 C. Wang, X. Liu, M. E. Fleet, J. Li, S. Feng, R. Xu and Z. Jin, CrystEngComm, 2010, 12, 1617.

17 W. Liu, M. Yang, Y. Ji, F. Y. Liu, Y. Wang, X. F. Wang, X. D. Zhao and X. Y. Liu, RSC Adv., 2014, 4, 26951.

18 W. Liu, Y. Ji, F. Y. Liu, Y. Wang, X. D. Zhao and X. Y. Liu, RSC Adv., 2015, 5, 29121.

19 L. Chang, X. Liu, C. Wu, X. Liu and G. Li, Phys. Chem. Miner., 2015, 42, 223.

20 Q. He, X. Liu, B. Li, L. Deng, Z. Chen, X. Liu and H. Wang, Phys. Chem. Miner., 2013, 40, 29.

21 X. Liu and M. Fleet, J. Mineral. Petrol. Sci., 2009, 104, 25.

22 J. F. Moulder, W. F. Stickle, P. E. Sobol and K. D. Boomben, Handbook of X-ray Photoelectron Spectroscopy, Physical Electronics, 1995.

23 T. K. Hirsch and L. Ojamäe, Acta Crystallogr., Sect. B: Struct. Sci., 2004, 60, 179.

24 T. K. Hirsch, Z. Anorg. Allg. Chem., 2003, 629, 666.

25 R. D. Shannon, B. E. Taylor, T. E. Gier, H. Y. Chen and T. Berzins, Inorg. Chem., 1978, 17, 958.

26 I. D. Brown and D. Altermatt, Acta Crystallogr., Sect. B: Struct. Sci., 1985, 41, 244.

27 N. E. Brese and M. O'Keeffe, Acta Crystallogr., Sect. B: Struct. Sci., 1991, 47, 192.

28 P. Dorenbos, J. Lumin., 2000, 91, 91.

29 P. Dorenbos, J. Phys.: Condens. Matter, 2003, 15, 6249.

30 H. Ebendorff-Heidepriem and D. Ehrt, Opt. Mater., 2002, 18, 419.

31 G. Blasse, Prog. Solid State Chem., 1988, 18, 79.

32 W. H. Di, X. J. Wang, B. J. Chen, S. Z. Lu and X. X. Zhao, J. Phys. Chem. B, 2005, 109, 13154.

33 S. H. M. Poort, H. M. Reijnhoudt, H. O. T. Kuip and G. Blasse, J. Alloys Compd., 1996, 241, 75.

34 Z. G. Cui, G. H. Jia and D. G. Deng, J. Lumin., 2012, 132, 153. 35 M. A. Mickens and Z. Assefa, J. Lumin., 2014, 145, 498.

36 Z. G. Xia, Y. Y. Zhang, M. S. Molokeev, V. V. Atuchin and Y. Luo, Sci. Rep., 2013, 3, 3310. 